\title{
Expression of Class I and Class II Major Histocompatibility Antigens on Human Hepatocellular Carcinoma
}

\author{
Ching-Hwa Sung, ${ }^{*}$ Cheng-po Hu, ${ }^{\star *}$ Hey-Chi Hsu, ${ }^{3}$ Ah-Kau Ng," Chen-Kung Chou, ${ }^{\star *}$ Ling-Pai Ting, \\ Tsung-Sheng Su, ${ }^{\star *}$ Shou-Hwa Han, ${ }^{\star *}$ and Chungming Chang* \\ *Graduate Institute of Microbiology and Immunology, National Yang-Ming Medical College, Shih-Pai, Taipei 11221, Taiwan, \\ Republic of China; ${ }^{\ddagger}$ Department of Medical Research, Veterans General Hospital, Shih-Pai, Taipei 11217, Taiwan, Republic of China; \\ ${ }^{\S}$ Department of Pathology, School of Medicine, National Taiwan University, Taipei 10016, Taiwan, Republic of China; and \\ "Department of Pathology, College of Physicians and Surgeons, Columbia University, New York, New York 10032
}

\begin{abstract}
Previous reports indicate that human hepatocytes do not express class I and class II MHC antigens. Our analyses on 10 human hepatocellular carcinoma (HCC) cell lines by immunofluorescence tests and RIA, demonstrate that all the human HCC cell lines tested express class I MHC antigens and among them, three poorly differentiated human $\mathrm{HCC}$ cell lines also express class II MHC antigens. Results of immunoprecipitation and/or Western blotting experiments indicate similarity in the chemical nature of both the class I and class II MHC antigens expressed by the human HCC cell lines and by a human B lymphoblastoid cell line Raji. Furthermore, a new variant form of class $I$ antigen was detected in some of these HCC cell lines. Immunohistochemical studies of HCC tissues using the peroxidase-antiperoxidase staining method indicated that class I and class II antigens were detectable in 7 out of 11 and 3 out of $11 \mathrm{HCC}$ tissues from patients, respectively. The availability of MHC class I antigen-positive cultured HCC cell lines, including the poorly differentiated lines that also express MHC class II antigen, has provided us with interesting models to study the relationship between expression of $\mathrm{MHC}$ antigen and transformation and differentiation of human hepatocytes. These studies will also allow us some insight into the role of MHC class I and class II antigen in the immunosensitivity and immunogenecity of $\mathrm{HCC}$ cells to the host-immune response.
\end{abstract}

\section{Introduction}

The MHC is known to play a critical role in many aspects of immune response. In humans, the class I transplantation antigen encoded by the $A, B$, and $C$ loci of the $M H C$ was a $45-\mathrm{kD}$ glycoprotein associated with a $12-\mathrm{kD} \beta_{2}$-microglobulin $\left(\beta_{2}-\mathrm{m}\right)^{1}$

Address reprint requests to Dr. Chungming Chang, Graduate Institute of Microbiology and Immunology, National Yang-Ming Medical College, Shih-Pai, Taipei, Taiwan, Republic of China.

Received for publication 12 May 1987 and in revised form $29 \mathrm{Au}$ gust 1988.

1. Abbreviations used in this paper: $\beta_{2}-\mathrm{m}, \beta_{2}$-microglobulin; HCC, human hepatocellular carcinoma; IFA, immunofluorescence staining; NET buffer, $50 \mathrm{mM}$ Tris, $150 \mathrm{mM} \mathrm{NaCl}, 0.5 \mathrm{mM}$ EDTA, $0.25 \%$ NP-40, 0.1\% BSA, 2 mM PMSF, pH 7.4; PAP, peroxidase-antiperoxidase; TTBS buffer, $0.05 \%$ Tween 20 in $50 \mathrm{mM}$ Tris- $\mathrm{HCl}$, $\mathrm{pH} 7.6$.

J. Clin. Invest.

(c) The American Society for Clinical Investigation, Inc. 0021-9738/89/02/0421/09 \$2.00

Volume 83, February 1989, 421-429 polypeptide. Their extreme polymorphism elicited strong allograft reactions. The class II antigen encoded by the HLA-D/ $\mathrm{DR}$ region consisted of a $34-\mathrm{kD} \alpha$ chain and a $28-\mathrm{kD} \beta$ chain and was involved in the regulation of immune response. It was reported that nearly all nucleated cells expressed class I MHC antigens, whereas class II MHC antigens appeared mainly on limited cell populations, e.g., B lymphocytes, macrophages, activated T lymphocytes, dendritic cells, and Kupffer cells, et cetera. (1). Furthermore, the expression of MHC antigens in many malignant tumors has been found to be different from that in normal cells (2-5). The differences vary from quantitative change to qualitative modification, as exemplified in several tumor cells that expressed attenuated structures of alien specificities distinct from those of their normal counterparts $(6,7)$. These alterations could be caused by mutation, recombination, or activation of normal MHC genes $(8,9)$. Recent studies on human and mouse liver tissues indicated that neither class I nor class II MHC antigens were detectable on the surface of normal hepatocytes (10-14). On the other hand, it was discovered that hepatocytes of human patients with acute and chronic active hepatitis expressed MHC class I antigens (11-13), and that $\mathrm{HBc}$ antigen-containing hepatocytes may also express class II antigen (15). These findings suggested that expression of MHC antigens in human hepatocytes could be induced under certain circumstances. Whereas long-term cultivation of normal human hepatocytes remains a laboratory challenge, several permanent human hepatocellular carcinoma (HCC) cell lines have recently become available (16-24). These cell lines are useful tools not only for the study of MHC gene expression and regulation in hepatocytes, but also for the investigation of the association of $\mathrm{MHC}$ antigens with transformation of human hepatocytes. In this report, MAb against MHC class I and class II antigens were used to demonstrate that $\mathrm{MHC}$ antigens are expressed on cultured HCC cell lines. The biochemical nature of the MHC antigens expressed on the HCC cell lines was also characterized in seven representative cell lines. To demonstrate the biological significance of MHC antigens in vivo, the expression of MHC class I and class II antigens on HCC tissues was tested and positive results were obtained. Our results suggest that $\mathrm{HCC}$ cell lines present useful models for investigating the association of $\mathrm{MHC}$ antigens with hepatocyte differentiation and transformation, and for explaining the role of these antigens in host immunity to HCC.

\section{Methods}

Cell culture. 10 human HCC cell lines, PLC/PRF/5 (16), SK-Hep-1 (17), Tong (18), Mahlavu (16), Hep G2 $(19,20)$, Hep 3B (19, 20), HA22T/VGH (21), HA47T/VGH (22), HuH-6 cl 5 (23), and HuH-7 
(24) were used in this study. They had been cultured for 100-200 passages in complete DME, supplemented with $10 \%$ fetal bovine serum, $2 \mathrm{mM}$ glutamine, $100 \mathrm{IU}$ penicillin $/ \mathrm{ml}$, and $100 \mu \mathrm{g}$ streptomy$\mathrm{cin} / \mathrm{ml}$. The erythromyeloid cell line, K562, and lymphoblastoid cell line, Raji, were maintained in RPMI 1640 medium with the same supplements as described for DME complete medium. All these cells were incubated at $37^{\circ} \mathrm{C}$ in a $\mathrm{CO}_{2}$ incubator with $5 \% \mathrm{CO}_{2}$.

Antibodies. Several MAb reacted to human MHC antigens (HLA) were used in this study. MAb W6/32 (25) (Serotec Ltd., Bicester, UK), MAbc. I (Ng et al., unpublished observations), and anti-HLA-A,B,C (Cooper Biomedicals, Malvern, PA) reacted with the nonpolymorphic determinant of the heavy chain of HLA class I antigens; MAb NAMB-1 reacted with $\beta_{2}$-microglobulin (5); and MAb Q5/13 (26); OK-DR and OK-Ia*1, purchased from Ortho Diagnostics (Raritan, $\mathrm{NJ})$, recognized the framework region of HLA class II antigens.

Immunostaining analysis of cultured cells. Target cells for immunofluorescence assay (IFA) staining were prepared by two methods. Cultured monolayer cells were grown on glass slides for $24 \mathrm{~h}(60-80 \%$ confluency) and then fixed with ice-cold acetone for $10 \mathrm{~min}$. Alternatively, viable cells were harvested from monolayer tissue culture at $80 \%$ confluency by $2 \mathrm{mM}$ EDTA treatment, washed, and resuspended in PBS. The target cells were preincubated with $5 \%$ normal goat blocking serum and then reacted with undiluted supernatant of MAb for $30 \mathrm{~min}$ at $4^{\circ} \mathrm{C}$. After three washings with PBS, fluorescein-conjugated goat anti-mouse Ig (Cappel Laboratories, West Chester, PA) was added for $30 \mathrm{~min}$ at $4^{\circ} \mathrm{C}$. Finally, the cells were washed and mounted in $90 \%$ glycerol-PBS for observation. For peroxidase-antiperoxidase (PAP) staining, 24-h cultured monolayer cells grown on glass slides were fixed with acetone as in IFA tests and reacted with MAb as in the tissue staining technique described below.

Immunohistochemical staining of human tissues. 11 pathologically proved human HCC tissues and 6 adjacent normal liver tissues were surgically obtained from $11 \mathrm{HCC}$ patients (according to the regulations of the Veterans General Hospital and the National Taiwan University Hospital) and immediately frozen in liquid nitrogen. $7-\mu \mathrm{m}$ frozen sections were prepared, air dried, and fixed in cold acetone for $10 \mathrm{~min}$. Fixed sections were incubated first with normal goat serum for blocking and subsequently with undiluted supernatant of MAb for $30 \mathrm{~min}$ and then washed with PBS. After incubation with goat anti-mouse Ig (Cappel Laboratories) for $30 \mathrm{~min}, 3 \% \mathrm{H}_{2} \mathrm{O}_{2}$ containing methanol was added to block endogenous peroxidase. Finally, after the addition of PAP complex (Jackson ImmunoResearch Lab, Avondale, PA) for a reaction time of $30 \mathrm{~min}$, freshly prepared substrate $\left(0.05 \% 3,3^{\prime}\right.$-diaminobenzidine tetrahydrochloride and $0.01 \%$ hydrogen peroxide in 0.05 M Tris buffer, pH 7.2) was added for color development. One of the consecutive sections was counterstained with Meyers' hematoxylin and mounted for examination.

Radioimmunobinding assay. The radioimmunobinding assay was performed according to the procedures described previously (27). Goat anti-mouse Ig used in this assay was iodinated by the chloramine $\mathrm{T}$ method (28). In a 96-well polyvinyl microtiter plate (Costar Corp., Cambridge, MA), target cells $\left(5 \times 10^{5}\right.$ cells/well) were preincubated with normal goat serum, then incubated with undiluted culture supernatants of MAb W6/32, MAb NAMB-1, or MAb Q5/13 for 30 min at $4^{\circ} \mathrm{C}$. For control, supernatant of cultured myeloma cells NS-1 was used. After incubation, cells were subsequently washed three times and ${ }^{125}$ I-labeled goat anti-mouse $\mathrm{Ig}\left(1 \times 10^{5} \mathrm{cpm} /\right.$ well $)$ was added for an additional $30 \mathrm{~min}$. Finally, microtiter plates were washed to remove unbound secondary antibodies and radioactivity bound to target cells was determined by a gamma counter.

SDS-PAGE analysis of MHC antigens. For metabolic labeling, cultured HCC cells were labeled with $\left[{ }^{35}\right.$ S $]$ methionine (New England Nuclear, Boston, MA) for 4-6 h. Cells to be labeled in the presence of tunicamycin, an inhibitor of $\mathrm{N}$-linked glycosylation, were pretreated with $1 \mu \mathrm{g} / \mathrm{ml}$ tunicamycin for $30 \mathrm{~min}$ before labeling according to procedures described previously by us and others (29). The optimal condition of tunicamycin treatment was predetermined and under this condition it was found that antibiotics inhibited glycosylation of Raji and HA22T/VGH cells without showing significant effects on protein synthesis of these cells. Labeled cells were washed with cold PBS, and solubilized in NET buffer ( $50 \mathrm{mM}$ Tris, $150 \mathrm{mM} \mathrm{NaCl}, 0.5 \mathrm{mM}$ EDTA, $0.25 \%$ NP-40, 0.1\% BSA, 2 mM PMSF, pH 7.4) for $4 \mathrm{~h}$ at $4^{\circ} \mathrm{C}$. Solubilized lysates were collected after centrifugation at $12,000 \mathrm{rpm}$ for $40 \mathrm{~min}$.

Ascites containing high titered MAbs were first absorbed to protein A Sepharose (Pharmacia Fine Chemicals, Uppsala, Sweden) according to the procedure described previously (25). Ascites of NS-1 myeloma was used for control. Cell lysates were first precleared with protein A Sepharose coupled with normal mouse serum and subsequently incubated with protein A Sepharose coupled with specific antibodies for $4 \mathrm{~h}$ at $4^{\circ} \mathrm{C}$. After extensive washing with NET buffer, labeled antigens were eluted from the immunoprecipitates by boiling $5 \mathrm{~min}$ with sample buffer, (3\% SDS, 5\% 2-mercaptoethanol, $10 \%$ glycerol, $0.05 \%$ bromophenol blue, $6.25 \mathrm{mM}$ Tris-HCl, pH 7.0) and electrophoresed on $15 \%$ SDS-PAGE according to the method of Laemmli (30). Gels had been stained, destained, and treated for fluorography before they were dried and exposed at $-70^{\circ} \mathrm{C}$ on Kodak X-Omat R films.

Western blotting analysis. Detached cultured cells were washed with PBS and lysed with extraction buffer $(0.5 \%$ sodium deoxycholate, $0.5 \%$ Triton X-100, $10 \%$ glycerol, $2 \mathrm{mM}$ PMSF, $10 \mathrm{mM}$ Tris, pH 9.0). Solubilized proteins were analyzed with a protein kit (Bio-Rad Laboratories, Richmond, CA) and then subjected to SDS-PAGE on 15\% gels. After electrophoresis, the separated proteins were electrotransferred to nitrocellulose paper. The nitrocellulose paper was incubated with 5\% defatted milk for overnight at room temperature. Then, MAb antiHLA-A,B,C $(1.5 \mu \mathrm{g} / \mathrm{ml})$ and MAb NAMB-1 undiluted supernatants were added for $2 \mathrm{~h}$ at room temperature with constant stirring. After three washings with TTBS buffer $(0.05 \%$ Tween 20 in $50 \mathrm{mM}$ Tris$\mathrm{HCl}, \mathrm{pH}$ 7.6), alkaline phosphatase-labeled secondary antibody (Sigma Chemical Co., St. Louis, MO) diluted with $1 \%$ defatted milk for 1,000-fold was added and incubated for $1 \mathrm{~h}$. Color was developed by the addition of $50 \mathrm{mM}$ Tris- $\mathrm{HCl}(\mathrm{pH} 8.2)$ containing $0.5 \%$ fast red (Sigma Chemical Co.) and $0.2 \% \alpha$-napthylphosphate (Sigma Chemical Co.).

Table I. Expression of HLA Antigens on Human Cell Lines Tested with MAbs in Immunostaining Assays

\begin{tabular}{lccc}
\hline \multicolumn{1}{c}{ Cell line } & HLA-A,B,C & $\beta_{2}$-m & HLA-DR \\
\hline $\begin{array}{l}\text { Hepatocellular carcinoma } \\
\quad \text { cell }\end{array}$ & & & \\
SK-Hep-1 & + & + & + \\
HA22T/VGH & + & + & + \\
HA47T/VGH & + & + & + \\
TONG & + & + & - \\
Hep3B & + & + & - \\
HepG2 & + & + & - \\
PLC/PRF/5 & + & + & - \\
Mahlavu & + & + & - \\
HuH-6 cl 5 & + & + & - \\
HuH-7 & + & + & - \\
B lymphoblastoid cell & & & \\
Raji & + & + & + \\
Erythromyeloid cell & & & \\
K562 & - & - & - \\
\hline
\end{tabular}

Class I antigens were measured with MAbs MAbc- 1 (anti-HLA$\mathrm{A}, \mathrm{B}, \mathrm{C}, \mathrm{OK}-\mathrm{DR}$, and NAMB-1 (anti- $\beta_{2} \mathrm{~m}$ ). Three MAbs, Q5/13, OK-DR, and OK-Ia* 1 were used to identify class II molecules. Raji cells and $\mathrm{K} 562$ cells were used as positive and negative controls. 


\section{Results}

Detection of HLA antigens on cultured human HCC cell lines by immunostaining assays. 10 human HCC cell lines, SKHep-1, HA22T/VGH, HA47T/VGH, Tong, Hep 3B, Hep G2, PLC/PRF/5, Mahlavu, HuH-6 cl 5, and HuH-7, were tested for the expression of class I and class II antigens by the immunofluorescence and PAP methods using an anti-HLA-A,B,C MAb (MAbc. 1), an anti- $\beta_{2}$ m MoAb (NAMB-1), and three MAbs recognizing HLA class II antigens (Q5/13, OK-DR, and OK-Ia*1). Raji cells, which expressed both class I and class II antigens, and K562 cells, which lack both antigens, were used as positive and negative controls for class I and class II antigens respectively. Results indicated that all $10 \mathrm{HCC}$ cell lines reacted specifically with both the anti-class $I$ antigen and anti- $\beta_{2}$-m MAb (Table I). When the viable HCC cells were stained with the anti-class I MAb, fluorescent stainings appeared on nearly all the cell membranes. Fig. $1 A$ gives the result of the fluorescent staining of a representative cell line, HA22T/VGH. When the HCC cells fixed by acetone were stained with anti-class I MAbs in either fluorescent or PAP staining, a strong staining was also observed on perinuclear regions of the HCC cells (Fig. $1 C$ ). The immunofluorescent and PAP stainings of HCC cell lines with anti-class II MAb showed positive reactivity with three HCC cell lines, HA22T/ VGH, HA47T/VGH, and SK-Hep-1 (Table I). Consistently, class II antigen was observed on $\sim 20-30 \%$ of the cultured cells of these positive HCC cell lines by IFA test and was located along cell membrane and perinuclear regions (Fig. 1, B and $D$ ).

Expression of class I and class II antigens detected by radioimmunobinding assays. The results of the immunofluorescence study suggested that expression of class I and class II antigens varied in quantity among different $\mathrm{HCC}$ cell lines. Subsequently, a semiquantitative radioimmunobinding assay was used to measure the amount of HLA antigens expressed
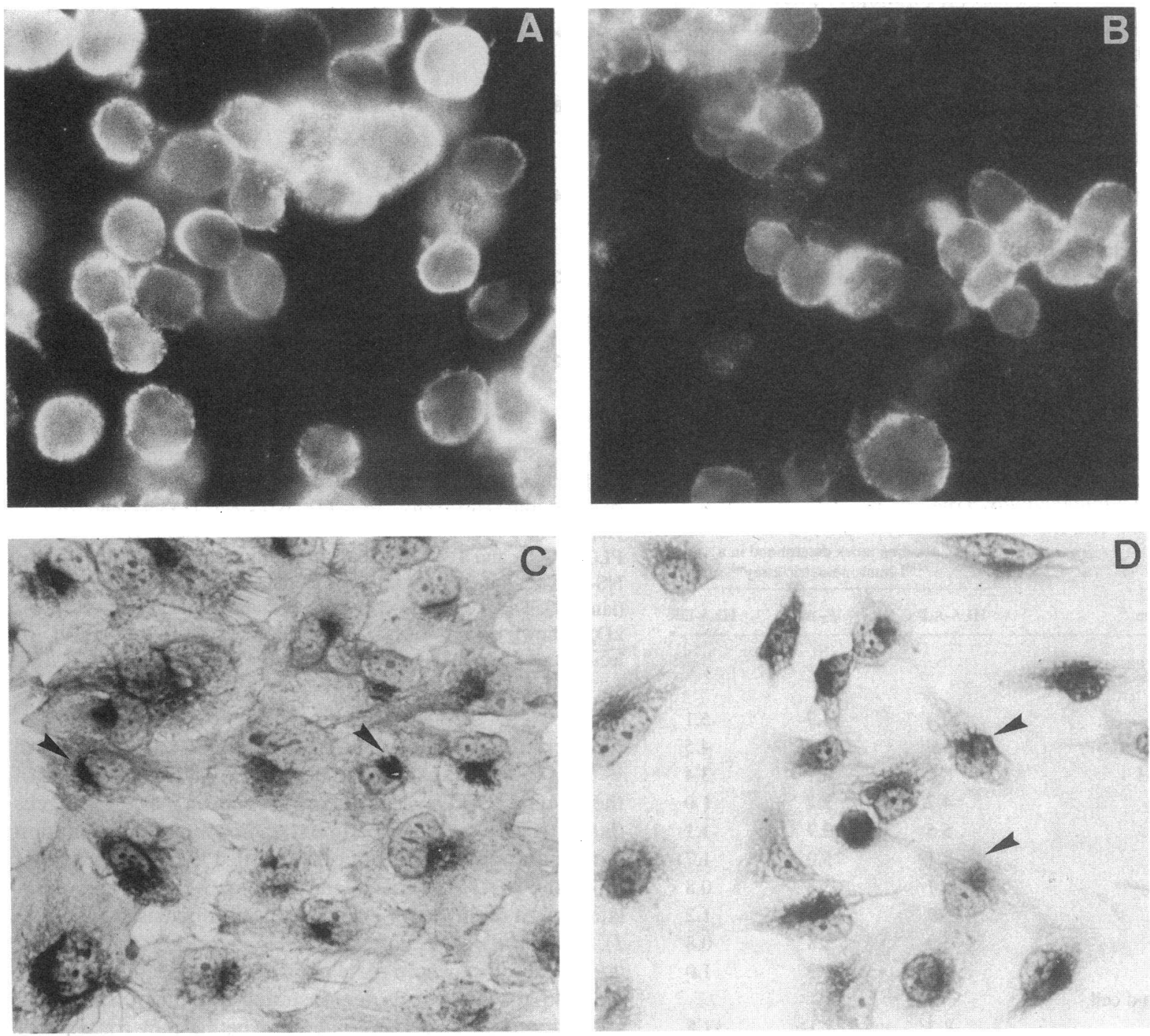

Figure 1. Immunostaining of MHC antigens on cultured human HCC cells $(\times 370)$. $(A)$ Class I antigens and $(B)$ class II antigens expressed on the cell surface of viable HA22T/VGH cells were detected with MAb MAbc-1 and MAb Q5/13, respectively, in indirect immunofluorescence staining. Acetone-fixed HA22T/VGH cells reacted with $(C)$ MAb MAbc-1 and $(D)$ MAb Q5/13 in PAP staining show apparent perinuclear staining by either of the two MAbs (arrowheads). 
on cultured HCC cells. The results, presented as binding indices (Table II), confirmed that all the $10 \mathrm{HCC}$ cell lines expressed class I antigens. Accordingly, $\beta_{2}-\mathrm{m}$ linked to class I antigen on cell surface was also detected on all the human HCC cell lines. Comparatively, SK-Hep-1 and HA47T/VGH had the highest amount of class I antigens similar to those found on Raji cells. On the contrary, the HuH- 6 cl 5 cell line seemed to express a lower amount of class I antigens. The data from the radioimmunobinding assays further demonstrated that only SK-Hep-1, HA22T/VGH, and HA47T/VGH expressed class II antigens. As shown in Table II, the amount of class II antigens expressed on HCC cells was only about one half to one third that detected on B lymphoblastoid Raji cells.

Characterization of class I MHC antigens on HCC cell lines. To understand the chemical nature of class I and class II antigens expressed on HCC cells, detergent extracts of $\left[{ }^{35} \mathrm{~S}\right]-$ methionine labeled cells of HCC cell lines HA22T/VGH, HA47T/VGH, SK-Hep-1, HuH-7, Hep 3B, PLC/PRF/5, and Tong were immunoprecipitated with ascites of MAb against HLA antigens. For comparison, immunoprecipitation of Raji cell lysate was also carried out in parallel. As shown in Fig. 2, $A$ and $B$, the anti-class I antibody (MAb W6/32) precipitated a major protein component with a molecular weight of $\sim 45,000$ from all the cell lines. Also noticeable are minor protein bands migrating near the $45-\mathrm{kD}$ region, which could be attributed to differential glycosylation of HLA-A,B,C antigen during biosynthesis. In addition, a 39,000-mol wt component was consistently precipitated from $\mathrm{HA} 22 \mathrm{~T} / \mathrm{VGH}$ cells with the anti-class I antibody. To determine whether this 39-kD molecule was an unglycosylated form or a new variant of the heavy chain of class I antigens, radiolabeled lysate of HA22T/VGH cells treated with tunicamycin was immunoprecipitated with the anti-class I antibody. As shown in Fig. 3 (lane 4), tunicamycin-treated HA22T/VGH cells yielded two

Table II. HLA Antigenic Profiles of Human Hepatoma Cell Lines by Radioimmunobinding Assay

\begin{tabular}{lccc}
\hline & \multicolumn{3}{c}{$\begin{array}{c}\text { Binding index determined in a } \\
\text { 125I-immunometric assay*t }\end{array}$} \\
\cline { 2 - 4 } \multicolumn{1}{c}{ Cell line } & HLA-A,B,C & $\beta_{2}$-m & HLA-DR \\
\hline Hepatocellular carcinoma & & & \\
$\quad$ cell & & & \\
SK-Hep-1 & 10.4 & 4.7 & 5.1 \\
HA22T/VGH & 6.9 & 5.9 & 4.5 \\
HA47T/VGH & 8.1 & 6.1 & 3.4 \\
TONG & 4.7 & 7.2 & 1.0 \\
Hep3B & 5.5 & 3.7 & 1.1 \\
HepG2 & 4.1 & 5.0 & 1.7 \\
PLC/PRF/5 & 6.7 & 5.3 & 0.8 \\
Mahlavu & 5.9 & 6.1 & 1.2 \\
HuH 6 cl-5 & 3.0 & 2.8 & 0.8 \\
HuH-7 & 5.9 & 3.9 & 1.0 \\
B lymphoblastoid cell & & & \\
Raji & 8.3 & 7.1 & 11.8 \\
& & & \\
\hline
\end{tabular}

\footnotetext{
* Results are the average of triplicate determinations.

${ }^{\ddagger}$ Binding index = counts per minute of cells reacted with culture supernatant of specific MAb/counts per minute of cells reacted with culture supernatant of NS-1 myeloma.
}

2A

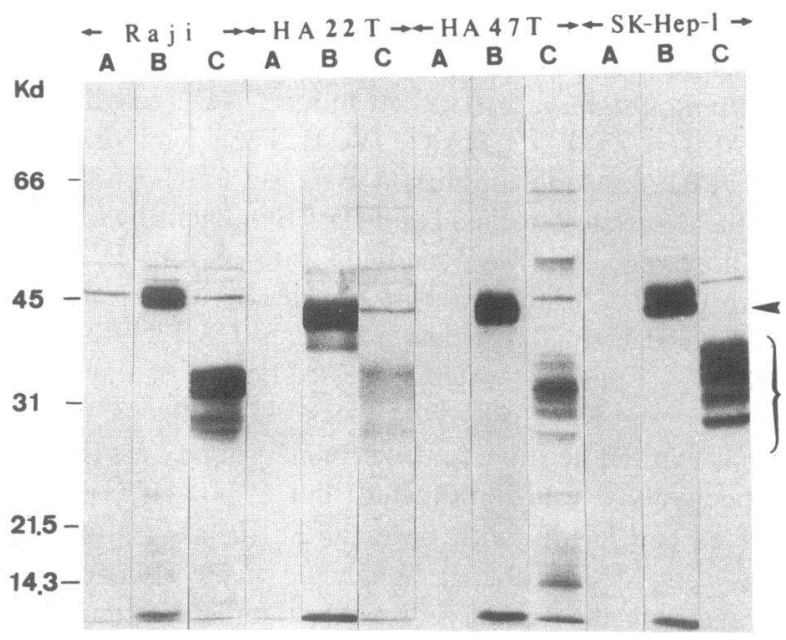

2B

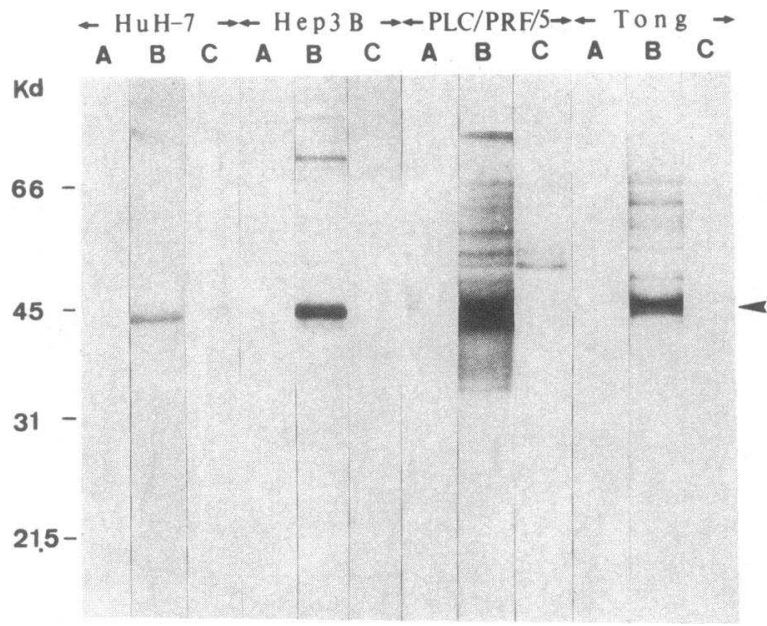

Figure 2. SDS-PAGE of HLA antigens immunoprecipitated from $\left.{ }^{35} \mathrm{~S}\right]$ methionine-labeled cell lysates. The labeled cell lysates of Raji cells and three HCC cells, HA22T/VGH, HA47T/VGH, and SKHep-1 (Fig. $2 A$ ); and those of four other HCC cells, HuH-7, Hep 3B, PLC/PRF/5, and Tong (Fig. $2 B$ ) were immunoprecipitated with NS-1 ascites (lanes $A$ ), MAb W6/32 (lanes $B$ ), and MAb Q5/13 (lanes $C$ ). The position of class I heavy chain (molecular mass 45 $\mathrm{kD}$ ) is shown by arrowheads. The position of class II antigens (molecular mass $28-36 \mathrm{kD})$ is shown by braces $(\{)$.

polypeptides with molecular weights of $\sim 41,000$ and $\sim 36,000$, which may represent unglycosylated precursors of the $45-$ and $39-\mathrm{kD}$ forms of heavy chains of class I antigens (lane 3). In the control experiment, radioimmunoprecipitation of tunicamycin-treated Raji cells revealed two components of $\sim 44$ and $\sim 41 \mathrm{kD}$ (Fig. 3, lane 2 ) which were the unglycosylated forms of the heavy chains of class I antigens (Fig. 3, lane 1). As controls, ascites of NS-1 myeloma cells did not precipitate any specific antigen (data not shown). To identify whether the $\sim 45-\mathrm{kD}$ multibands demonstrated with anti-class I MAb were all genuine class I molecules or whether they consisted of other components physically associated with class I antigens, Western blotting analysis was performed. As neither MAb MAbc. 1 nor W6/32 reacted with the SDS-denatured class I molecules, another MAb, Anti-HLA-A,B,C, (anti-class I), mixed together with MAb NAMB-1 (anti- $\beta_{2}-\mathrm{m}$ ), was used in 


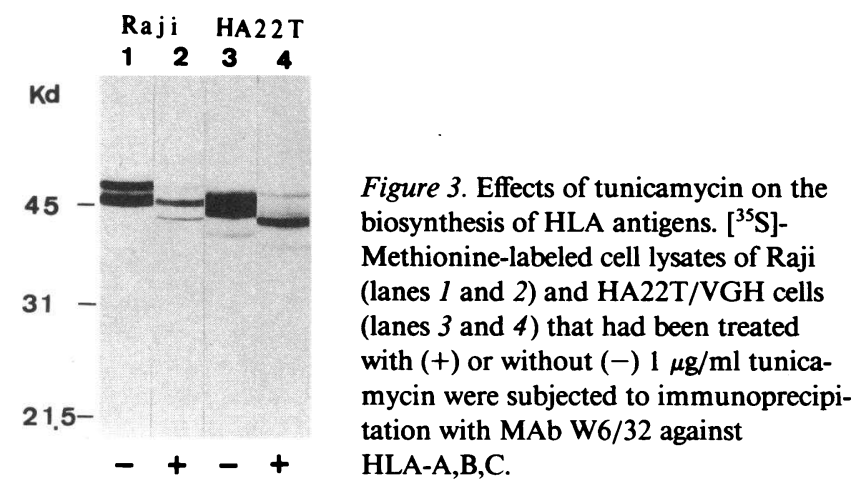

the Western blotting test. As shown in Fig. 4, the class I antigen bands visualized in Western blotting analysis had a pattern very similar to that observed in immunoprecipitation. All the HCC cell lines, HuH-7, HA22T/VGH, SK-Hep-1, Hep 3B, PLC/PRF/5, Mahlavu, and Tong showed a major $\sim 45-\mathrm{kD}$ component that was indistinguishable from the class I antigen shown by molecular weight of Raji cells. In HA22T/VGH cells and Mahlavu cells (lanes 3 and 7, respectively), doublet bands with molecular weights of $\sim 45$ and $\sim 39 \mathrm{kD}$ were clearly observed. The $\beta_{2}-\mathrm{m}$ with the typical molecular mass of $12 \mathrm{kD}$ was clearly identified on the HA22T/VGH, Mahlavu, and Raji cell lines.

Characterization of class II MHC antigens expressed by human HCC cell lines. When lysate of the $\left[{ }^{35}\right.$ S]methioninelabeled Raji cells was reacted with the anti-class II antigen $\operatorname{MoAb}(\mathrm{Q} 5 / 13)$, antigens between 34 and $28 \mathrm{kD}$, representing the Ia-like molecules were immunoprecipitated (Fig. $2 \mathrm{~A}$ ). Diffused protein bands with similar molecular weights were found when the same MAbs were reacted with the extracts of $\left[{ }^{35}\right.$ S]methionine-labeled HA22T/VGH and HA47T/VGH cells. In SK-Hep-1 cells, an additional antigen of $36 \mathrm{kD}$ was clearly precipitated by the anti-class II MAb. On the contrary, class II antigens were not detectable in the lysates of the other four HCC cell lines, HuH-7, Hep3B, PLC/PRF/5, and Tong.

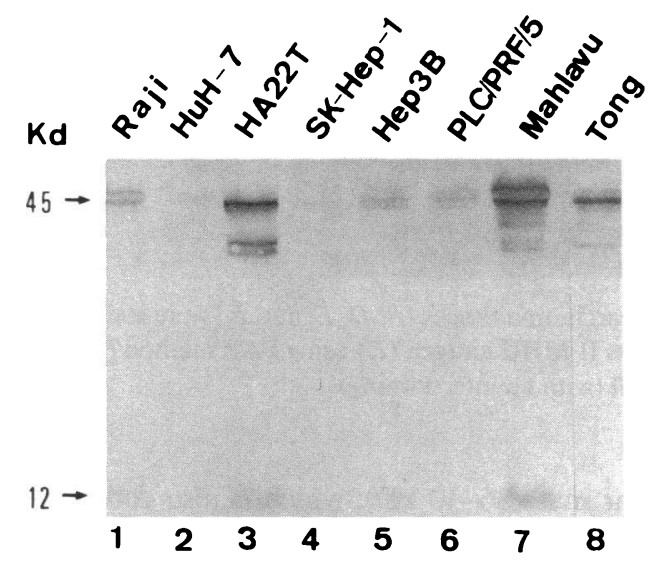

Figure 4. Detection of class I antigen on a Raji cell (lane 1 ) and seven HCC cells (lanes $2-8$ ). Samples (each lane loaded with $\sim 150$ $\mu \mathrm{g})$ of cell lysates were electrophoresed on $15 \%$ SDS-PAGE and analyzed by immunoblotting. Mixture of MAb Anti-HLA-A,B,C (1.5 $\mu \mathrm{g} / \mathrm{ml}$ ) and MAb NAMB-1 was used as the primary antibody in the immunoblotting. Alkaline phosphatase-coupled secondary antibody and substrate were sequentially added onto the nitrocellular paper for color development of class I antigen bands.
Expression of MHC antigens on human HCC tissues. The expression of MHC antigen in human HCC and their adjacent nontumorous liver tissues was examined by PAP staining using MAb against class I and class II antigens. The results are shown in Fig. 5, $A-F$ and summarized in Table III. Five out of six nontumorous liver tissues did not have any detectable class I antigen on hepatocytes (Fig. 5, $A$ and $C$ ). Only one out of six nontumorous liver tissues had HLA-A,B,C class I antigens on hepatocyes. The results shown in our studies were also consistent with previous reports that in normal liver HLA-A,B,C antigen and $\beta_{2}$-m were mainly expressed on liver sinusoidal lining cells rather than on hepatocytes (25). The expression of class I antigens on one nontumorous tissue may be due to a previous chronic hepatitis B virus infection as described before (11-13). In contrast to normal liver tissues, the majority of the HCC tissues tested (7 out of 11) showed expression of class I antigen on the surface of hepatocytes. One representative example was shown in Fig. 5 B. Among the seven positive HCC tissues, four were also positive in the expression of $\beta_{2}$-m (see Fig. $5 \mathrm{D}$ ). Although, the intensity of PAP staining of class I antigen and $\beta_{2}$-m on HCC tissues was not as strong as that which appeared on either the infiltrating lymphocytes or liver sinusoidal lining cells, the presence of class I antigen and $\beta_{2}-\mathrm{m}$ on those HCC tissues were apparent as compared with the controls, using NS-1 myeloma supernatants (Fig. $5 F$ ).

When the expression of class II antigens in the normal liver was studied, positive reactivity was found in Kupffer cells and in sinusoidal endothelial cells. In the HCC tissues, only 3 out of 11 samples showed focal and faint staining of class II antigens on the surface of the hepatocytes as compared with the negative controls NS-1 and MAb OKT3 (Fig. $5 E$ ). Some isolated class II-containing HCC cells were also found scattering in these three HCC tissues (data not shown).

\section{Discussion}

Our analyses of human HCC cell lines with MAb showed that all 10 human HCC cell lines studied expressed class I MHC antigens. Furthermore, three of the cell lines, SK-Hep-1, HA22T/VGH, and HA47T/VGH, also expressed class II MHC antigens. The results of immunofluorescent and PAP tests revealed that both class I and class II antigens were expressed on cell surfaces. Whereas class I antigens were present on almost all cells in each cell line, only a subpopulation of the SK-Hep-1, HA22T/VGH, and HA47T/VGH contained class II antigens. Interestingly, perinuclear localization of HLA antigens in human HCC cells was also observed by the immunostaining tests. A similar phenomenon had been reported by Burgert et al. (32), due to the E3/19 K protein-formed complex with MHC class I antigens in adenovirus type 2-infected cells. In the case of human HCC cells, whether any macromolecules are associated with class I MHC antigens that result in their perinuclear localization remains to be analyzed.

The chemical nature of the class I and class II MHC antigens of seven human HCC cell lines, HA22T/VGH, HA47T/ VGH, SK-Hep-1, HuH-7, Hep 3B, PLC/PRF/5, and Tong, was determined by radioimmunoprecipitation and Western blotting tests. The anti-class I MAbs used in these studies detected an antigen with molecular weight of $\sim 39,000$ in HA22T/VGH and Mahlavu cells, in addition to the regular $\sim 45-\mathrm{kD}$ MHC class I antigen that was found in all HCC cell 

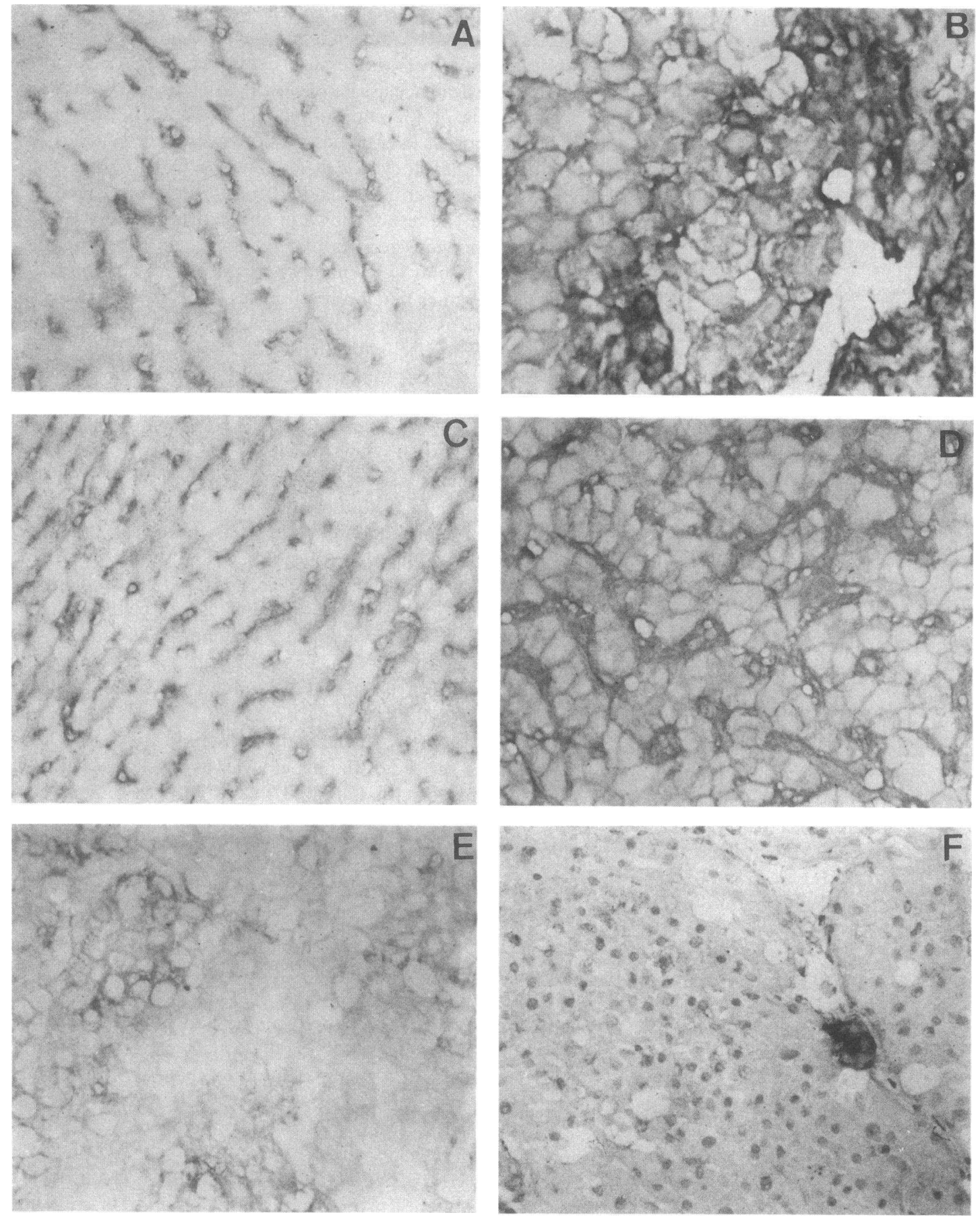

Figure 5. Cryostat sections of human nontumorous liver tissue $(A$ and $C$ ) and hepatocellular carcinoma tissues $(B, D, E$, and $F)$ were stained with MAb against HLA-A,B,C antigen $(A$ and $B), \beta_{2}$-microglobulin antigen $(C$ and $D)$ and class II MHC antigen $(E)$ using PAP method (without counterstaining). $F$ shows negative controls stained with supernatant of NS-1 myeloma cell (with counterstaining).

lines. Further studies performed on the tunicamycin-treated HA22T/VGH cells indicated that the 39-kD molecule was not an incomplete $\mathrm{N}$-glycosylated form of HLA-A,B,C antigen. That similar antigen could be detected by Western blotting excluded the possibility that this molecule was coprecipitated with the $45-\mathrm{kD}$ putative class I antigen with MAb against MHC. It might represent a new variant of the class I antigen in some HCC cells. An interesting question remains; whether this antigen is translated from alternative-spliced mRNA species $(33,34)$ or analogous to the murine hepatocyte-specific Q10 antigen (molecular mass $36-40 \mathrm{kD}$ ), which is also coded by class I antigen gene complex (33). On the other hand, we could not completely rule out the possibility that the molecule represented a product or resulted from posttranslational modification in vivo. When class II MHC antigens of HA22T/VGH, HA47T/VGH, and SK-Hep-1 cells were studied immunochemically, diffused bands representing human Ia-like molecules were found. These results are similar to the previously reported observation that class II antigens have a differential degree of glycosylation (35). The additional antigens (molecu- 
Table III. Expression of Class I and Class II HLA Antigens in Hepatocyte of Primary Human HCC

\begin{tabular}{|c|c|c|c|c|c|c|c|c|}
\hline \multirow[b]{2}{*}{ Patient No. } & \multirow[b]{2}{*}{ Type* } & \multirow[b]{2}{*}{ Age/Sex } & \multicolumn{3}{|c|}{ Hepatocytes of nontumorous liver } & \multicolumn{3}{|c|}{ Hepatocytes of tumor } \\
\hline & & & HLA-ABC & $\beta_{2}-\mathrm{m}$ & DR & HLA-ABC & $\beta_{2}-\mathrm{m}$ & DR \\
\hline & & $y r$ & & & & & & \\
\hline EM 85-706 & SHCC & $54 / \mathrm{M}$ & - & - & - & + & + & - \\
\hline EM 84-232 & SHCC & $39 / \mathrm{M}$ & - & - & - & + & - & - \\
\hline EM 84-57 & SHCC & $52 / \mathrm{M}$ & - & - & - & + & + & - \\
\hline EM 84-64 & SHCC & $59 / \mathrm{M}$ & ND & ND & ND & + & - & - \\
\hline EM 84-73 & SHCC & $\mathbf{M}$ & - & - & - & + & ++ & + \\
\hline EM 84-318 & SHCC & $53 / \mathrm{M}$ & ND & ND & ND & - & - & - \\
\hline EM 84-670 & SHCC & $62 / \mathrm{M}$ & ND & ND & ND & - & - & + \\
\hline EM 84-297 & SHCC & $50 / \mathrm{M}$ & ND & ND & ND & - & - & - \\
\hline EM 85-1277 & LHCC & $51 / \mathrm{M}$ & + & - & - & + & - & - \\
\hline EM $85-648$ & LHCC & $48 / F$ & - & - & - & - & - & - \\
\hline EM $85-260$ & LHCC & $57 / \mathrm{M}$ & ND & ND & ND & ++ & ++ & + \\
\hline
\end{tabular}

* SHCC, small hepatocellular carcinoma; LHCC, large hepatocellular carcinoma; M, male; F, female; ND, not done.

lar mass $36 \mathrm{kD}$ ) of SK-Hep-1 cells reacted with anti-class II antibodies remains to be further analyzed.

In human liver, hepatocytes normally do not express class I MHC antigen (10-13). However, class I MHC antigen had been detected in vivo on hepatocytes of hepatitis patients and patients undergoing liver allograft rejection $(11-13,36)$. Our results indicated that class I MHC antigens were present on all 10 human HCC cell lines and most of HCC tissues. During the viral infection, liver allograft rejection and hepatocellular carcinogenesis, the immune response may be elicited to react against virally infected, allogeneic, or transformed hepatocytes. Lymphokines, such as IFN, a well-known class I MHC antigen inducer, may be released (37). Therefore, one possible mechanism for the appearance of class I MHC antigens on hepatocytes during viral infection, allograft rejection, and hepatocellular carcinoma is the inductive effect of lymphokines such as IFN on hepatocytes. The appearance of class I MHC antigens on all HCC cell lines suggests the other possibility, that class I MHC antigen is constitutively expressed on hepatocytes after transformation. Both experimental and epidemiological evidence indicate that hepatitis B virus infection plays an important role in the cause of human HCC (38). In addition, all 10 hepatoma patients listed in Table III, whose HBV markers been analyzed, had previous HBV infections (data not shown). These results suggest an interesting possibility, that HBV may directly cause the constitutive expression of class I MHC antigen on hepatocytes. Elevated expression of class I MHC antigen has been observed in cells transformed with polyma virus, SV40 virus, and retrovirus (39-41). However, the presence of class I MHC antigen on HuH-6 cl 5, HuH-7, SK-Hep-1, and Hep G2 cells, which do not have HBV genome (references 19 and 24; Chang, C., unpublished observation) indicated that the presence of integrated HBV genome is not necessarily required for the expression of class I antigen on human HCC cells.

Studies on MHC expression in HCC tissues revealed that most ( 7 out of 11) of HCC tissues expressed class I antigen. These results indicated that the appearance of class I MHC antigen on HCC cells also occurred in vivo, however, at a level lower than that detected on cultured HCC cells. Three hypoth- eses may be given to explain the quantitative difference observed. (a) The in vitro culture condition may favor the growth of class I antigen-positive cells or enhance the cellular expression of this antigen. ( $b$ ) an unknown mechanism of downregulation may be operated in HCC cells in vivo, leading to a reduced expression of class I molecule; and $(c)$ as suggested before in other tumor systems (42-45), HCC cells with a higher amount of MHC class I antigen may be more susceptible to host immunity.

The observation that class II antigens were only expressed in some areas of HCC tissues correlated with our findings in the cultured HCC cell lines. Only some HA22T/VGH, HA47T/VGH, and SK-Hep-1 cells express class II antigens. Note that, based on morphology, hepatocyte-associated enzymes, HBV gene expression, and protein secretions, all three class II MHC antigen-positive HCC cell lines, i.e., SK-Hep-1, HA22T/VGH, and HA47T/VGH, were classified as poorly differentiated $(21,22$, and 46). A previous study has demonstrated that the process of cellular differentiation in hematopoietic cells is accompanied by changes in the expression of class II antigens (47). It is possible that the expression of class II MHC antigens on human HCC cells line may also be related to the differentiation or progression stages of these cells. Alternatively, class II antigen expression by HCC cells may result from activation of silent genes after chromosomal insertion of $\mathrm{HBV}$ sequences. Although it remains speculative whether class II antigen expression in $\mathrm{HCC}$ cells is restricted to the poorly differentiated cells, this observation has prompted us to extend our studies to the relationship between expression of class II antigen and differentiation/transformation of human hepatocytes. Previous studies indicated that the presence of class I MHC antigens on tumor cells increased their susceptibility to cytotoxic $T$ cells in vitro (42) and to the immune surveillance against tumor cells in vivo (43-45). The class II MHC antigens have long been reported to be associated with antigen-presenting cells. The appearance of class I and class II MHC antigens on human HCC cells may have a significant effect on the reactivity of host immune system against HCC cells. These human HCC cell lines thus provide an excellent model to study the mechanisms of expression of MHC antigens on he- 
patocytes and the host-immune reaction against HCC cells, and to investigate the relationship of the appearance of these antigens and the transformation/differentiation of human HCC cells.

\section{Acknowledgments}

We thank Mrs. R. A. Phillips for her editorial assistance and Ms. Shiang-Lien $\mathrm{Lu}$ for the preparation of the manuscript.

This work was supported in part by grant NSC 76-0610-B010-38 and NSC 76-0412-B075-16 from the National Science Council of the Republic of China. Dr. A. K. Ng was supported by National Institutes of Health grant CA-34031.

\section{References}

1. Kaufman, J. F., C. Auffray, A. J. Korman, D. A. Shackelford, and J. Strominger. 1984. The class II molecules of the human and murine major histocompatibility complex. Cell. 36:1-13.

2. Goodenow, R. S., J. M. Vogel, and R. L. Linsk. 1985. Histocompatibility antigens on murine tumors. Science. (Wash. DC). 230:777783.

3. Doyle, A., W. J. Martin, K. Funa, A. Gazdar, D. Carney, S. E. Martin, I. Linnoila, F. Cuttitta, J. Mulshine, P. Bunn, and J. Minna. 1985. Markedly decreased expression of class I histocompatibility antigens, protein, and mRNA in human small-cell lung cancer. J. Exp. Med. 161:1135-1151.

4. Natali, P. G., P. Giacomini, A. Bigotti, K. Imai, M. R. Nicotra, A. K. Ng, and S. Ferrone. 1983. Heterogeneity in the expression of HLA and tumor-associated antigens by surgically removed and cultured breast carcinoma cells. Cancer Res. 43:660-668.

5. Ng, A. K., M. A. Pellegrino, K. Imai, and S. Ferrone. 1981. HLA-A,B antigens, Ia-like antigens, and tumor-associated antigens on prostate carcinoma cell lines: serologic and immunochemical analysis with monoclonal antibodies. J. Immunol. 127:443-447.

6. Gipson, T. G., M. Imamura, M. A. Conliffe, and W. J. Martin. 1978. Lung tumor-associated derepressed alloantigen coded for by the $\mathrm{K}$ region of the H-2 major histocompatibility complex. J. Exp. Med. 147:1363-1373.

7. Festenstein, H., and W. Schmidt. 1981. Variation in MHC antigenic profiles of tumor cells and its biological effects. Immunol. Rev. 60:85-127.

8. Gladstone, P., L. Fueresz, and D. Pious. 1982. Gene dosage and gene expression in the HLA region: evidence from deleton variants. Proc. Natl. Acad. Sci. USA. 79:1235-1239.

9. Holtkamp, B., M. Cramer, and K. Rajewsky. 1983. Somatic variation of $\mathbf{H}-2 \mathrm{~K}^{\mathbf{k}}$ expression and structure in a T-cell lymphoma: instability, stabilization, high production and structural mutation. EMBO (Eur. Mol. Biol. Organ.) J. 2:1943-1951.

10. Lautenschlager, I., E. Taskinen, K. Inkinen, V.-P. Lehto, I. Virtanen, and P. Hayry. 1984. Distribution of the major histocompatibility complex antigens on different components of human liver. Cell. Immunol. 85:191-200.

11. Barbatis, C., J. Woods, J. A. Morton, K. A. Fleming, A. McMichael, and J. O'D. McGee. 1981. Immunohistochemical analysis of HLA $(A, B, C)$ antigens in liver disease using a monoclonal antibody. Gut. 22:985-991.

12. Nagafuchi, Y., and P. J. Scheuer. 1986. Expression of $\beta_{2}$-microglobulin on hepatocytes in acute and chronic type B hepatitis. Hepatology (Baltimore). 6:20-23.

13. Montano, L., G. C. Miescher, A. H. Goodall, K. H. Wiedmann, G. Janossy, and H. C. Thomas. 1982. Hepatitis B virus and HLA antigen display in the liver during chronic hepatitis B virus infection. Hepatology (Baltimore). 2:557-561.

14. Momburg, F., N. Koch, P. Moller, G. Moldenhauer and G. J. Hammerling. 1986. In vivo induction of $\mathrm{H}-2 \mathrm{~K} / \mathrm{D}$ antigens by recombinant interferon-r. Eur. J. Immunol. 16:551-557.
15. van den Oord, J. J., D. V. Rita, and V. J. Desmet. 1986. In situ distribution of major histocompatibility complex products and viral antigens in chronic hepatitis B virus infection: evidence that $\mathrm{HBc}$-containing hepatocytes may express HLA-DR antigens. Hepatology (Baltimore). 6:981-989.

16. Alexander, J. J., E. M. Bey, E. W. Geddes, and G. Lecatsas. 1976. Establishment of a continuously growing cell line from primary carcinoma of the liver. S. Afr. Med. J. 50:2124-2128.

17. Fogh, J., J. M. Fogh, and O. Thomas. 1977. One hundred and twenty-seven cultured human tumor cell lines producing tumors in nude mice. J. Natl. Cancer Inst. 59:221-226.

18. Lin, J.-H., M. J. Tong, and D. Stevenson. 1984. A new human hepatocellular carcinoma cell line secreting hepatitis B surface antigen and alpha-fetoprotein. In Viral Hepatitis and Liver Disease. G. N. Vyas, J. L. Dienstag, and J. H. Hoofnagle, editors. Grune \& Stratton, Inc., Orlando, FL. 671. (Abstr.)

19. Aden, D. P., A. Fogel, S. Plotkin, I. Damjanov, and B. B. Knowles. 1979. Controlled synthesis of $\mathrm{HBs} \mathrm{Ag}$ in a differentiated human liver carcinoma-derived cell line. Nature (Lond.). 282:615616.

20. Knowles, B. B., C. C. Howe, and D. P. Aden. 1980. Human hepatocellular carcinoma cell lines secrete the major plasma proteins and hepatitis B surface antigen. Science (Wash. DC). 209:497-499.

21. Chang, C., Y. Lin, T.-W. O-Lee, C.-K. Chou, T.-S. Lee, T.-J. Liu, F.-K. P'eng, T.-Y. Chen, and C. Hu. 1983. Induction of plasma protein secretion in a newly established human hepatoma cell line. Mol. Cell. Biol. 3:1133-1137.

22. Chang, C., C. Hu, T. Tang, C. F. Chou, T. P. Ting, C. K. Chou, and S. H. Han. 1985. The differentiation properties of human hepatoma cell line. In Molecular Biology of Neoplasia. E. H. Chang, J. K. Lin, and P. C. Huang, editors. Academia Sinica. Taipei, ROC. 262-269.

23. Doi, I. 1976. Establishment of a cell line and its clonal sublines from a patient with hepatoblastoma. Gann. 67:1-10.

24. Nakabayashi, H., K. Taketa, K. Miyano, T. Yamane, and J. Sato. 1982. Growth of human hepatoma cell lines with differentiated functions in chemically defined medium. Cancer Res. 42:3858-3863.

25. Parham, P., C. J. Barnstable, and W. F. Bodmer. 1979. Use of a monoclonal antibody (W6/32) in structural studies of HLA-A,B,C antigens. J. Immunol. 123:342-349.

26. Quaranta, V., M. A. Pellegrino, and S. Ferrone. 1981. Serologic and immunochemical characterization of the specifity of four monoclonal antibodies to distinct antigenic determinants expressed on subpopulations of human Ia-like antigens. J. Immunol. 126:548-552.

27. McCabe, R. P., V. Quaranta, L. Frugis, S. Ferrone, and R. A. Reisfeld. 1979. A radioimmunometric antibody-binding assay for evaluation of xenoantisera to melanoma-associated antigens. J. Natl. Cancer Inst. 62:455-463.

28. Hunter, W. M., and F. C. Greenwood. 1962. Preparation of iodine-131 labelled human growth hormone of high specific activity. Nature (Lond.). 194:495-496.

29. Kantor, R. R. S., A. P. Albino, A. K. Ng, and S. Ferrone. 1986. Biosynthesis and intracellular processing of four human melanoma associated antigens. Cancer Res. 46:5223-5228.

30. Ploegh, H. L., H. T. Orr, and J. L. Strominger. 1981. Biosynthesis and cell surface localization of nonglycosylated human histocompatibility antigens. J. Immunol. 126:270-275.

31. Laemmli, U. K. 1970. Cleavage of structural protein during the assembly of the head of bacteriophage T4. Nature (Lond.). 227:680685 .

32. Burgert, H-G., and S. Kvist. 1985. An adenovirus type 2 glycoprotein blocks cell surface expression of human histocompatibility class I antigens. Cell. 41:987-997.

33. Maloy, W. L., J. E. Coligan, Y. Barra, and G. Jay. 1984. Detection of a secreted form of the murine $\mathrm{H}-2$ class I antigen with an antibody against its predicted carboxyl terminus. Proc. Natl. Acad. Sci. USA. 81:1216-1220.

34. Lalanne, J.-L., C. Transy, S. Guerin, S. Darche, P. Meulien, 
and P. Kourilsky. 1985. Expression of class I genes in the major histocompatibility complex: identification of eight distinct mRNAs in DBA/2 mouse liver. Cell. 41:469-478.

35. Shackelford, D. A., and J. L. Strominger. 1980. Demonstration of structural polymorphism among HLA-DR light chains by two-dimensional gel electrophoresis. J. Exp. Med. 151:144-163.

36. So, S. K. S., J. L. Platt, N. L. Ascher, and D. C. Snover. 1987. Increased expression of class I major histocompatibility complex antigens on hepatocytes in rejecting human liver allografts. Transplantion. 43:79-85.

37. Revel, M., and J. Chebath. 1986. Interferon-activated genes. Trends Biol. Sci. 11:166-170.

38. Beasley, R. P., L. Y. Hwang, C. C. Lin, and C. S. Chien. 1981. Hepatocellular carcinoma and hepatitis B virus: a prospective study of 22707 men in Taiwan. Lancet. ii:1129-1133.

39. Old, L. J. 1981. Cancer immunology: the search for specificity. G. H. A. Clows memorial lecture. Cancer Res. 41:361-375.

40. Majello, B., G. L. Mantia, A. Simeone, E. Boncinelli, and L. Lania. 1985. Activation of major histocompatibility complex class I mRNA containing an Alu-like repeat in polyoma virus-transformed rat cells. Nature (Lond.). 314:457-459.

41. Brickell, P. M., D. S. Latchman, D. Murphy, K. Willison, and P. W. J. Rigby. 1985. The class I major histocompatibility antigen gene activated in a line of SV40-transformed mouse cells is $\mathrm{H}-2 \mathrm{D}^{\mathrm{d}}$, not Qa/Tla. Nature (Lond.). 316:162-163.
42. Flyer, D. C., S. J. Burakoff, and D. V. Faller. 1985. Retrovirusinduced changes in major histocompatibility complex antigen expression influence susceptibility to lysis by cytotoxic T lymphocytes. $J$. Immunol. 135:2287-2292.

43. De Baetseiler, P., S. Katzar, E. Gerelik, M. Feldman, and S. Segal. 1980. Differential expression of $\mathbf{H}-2$ gene products in tumor cells is associated with their metastatogenic properties. Nature (Lond.). 288:179-181.

44. Shearman, P. J., W. M. Gallatin, and B. M. Longenecher. 1980. Detection of a cell-surface antigen correlated with organ-specific metastasis. Nature (Lond.). 286:367-369.

45. Tanaka, K., H. Hiroacki, H. Chuya, K. George, and J. Gilbert. 1986. Expression of major histocompatibility complex class I antigens as a strategy for the potentiation of immune recognition of tumor cells. Proc. Natl. Acad. Sci. USA. 83:8723-8727.

46. Chang, C., K. S. Jeng, C. Hu, S. J. Lo, T. S. Su, L. P. Ting, C. K. Chou, S. H. Han, E. Pfaff, J. Salfeld, and H. Schaller. 1987. Production of hepatitis B virus in vitro by transient expression of cloned HBV DNA in a hepatoma cell line. EMBO (Eur. Mol. Biol. Organ.) J. 6:675-680.

47. Winchester, R. J., G. D. Ross, C. I. Jarowski, C. Y. Wang, J. Halper, and H. E. Broxmeyer. 1977. Expression of Ia-like antigen molecules on human granulocytes during early phase of differentiation. Proc. Natl. Acad. Sci. USA. 74:4012-4016. 